Scientia Agricola

http://dx.doi.org/10.1590/0103-9016-2015-0196

\title{
Growth of Burkholderia sacchari LFM 101 cultivated in glucose, sucrose and glycerol at different temperatures
}

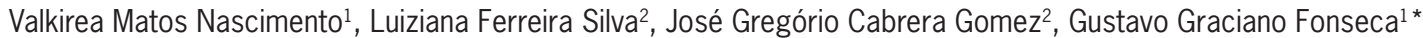

${ }^{1}$ Federal University of Grande Dourados/FCBA - Lab. of Bioengineering, Rod. Dourados/ttahum, km 12 - 79804-970

- Dourados, MS - Brazil.

2University of São Paulo/Institute of Biomedical Sciences

- Dept. of Microbiology, Av. Prof. Lineu Prestes, 1374 -

05508-900 - São Paulo, SP - Brazil.

*Corresponding author <gg@ufgd.edu.br>

Edited by: Airton Kunz

Received May 04, 2015

Accepted October 26, 2015
ABSTRACT: Polyhydroxyalkanoates (PHAs) have attracted major industrial interest as alternatives to conventional plastics. They are produced by several bacteria as cytoplasmic inclusions when nutrients are in limited supply. Among the many factors influencing bacterial growth, the effect of temperature on both specific growth rates and growth yields in terms of carbon source intake is of considerable interest. This study aimed to evaluate the influence of the bacterium Burkholderia sacchari LFM 101 on growth and PHA production, using glucose, sucrose or glycerol as a carbon source, at 30 and $35^{\circ} \mathrm{C}$. The results showed that $B$. sacchar cultured with glucose at $35^{\circ} \mathrm{C}$ presented both higher productivity and polymer yield in dried cell mass. There were no differences in growth rates $\left(\mu_{\max }\right)$ in sucrose and glucose. The growth conditions studied were not favorable to glycerol consumption due to limitations in the energy supply from glycerol.

Keywords: polyhydroxyalkanoates (PHAs), metabolism, kinetics

\section{Introduction}

Polyhydroxyalkanoates (PHAs) are biopolymers that can be accumulated in the form of cytoplasmic inclusions by several bacteria. Potential applications of the PHAs vary due to the diversity of possible monomer combinations (Mendonça et al., 2013; RodríguezContreras et al., 2015). Polyhydroxybutyrate (P3HB) is one of the most studied representatives of the PHA family. It has attracted attention because of its biodegradability, sustainability, durability and plasticity. It has properties similar to polypropylene (Mousavioun et al., 2013).

Burkholderia sacchari was reported as a Gramnegative bacterium with significant potential for industrial production of bioplastics (Silva et al., 2000; Squio and Aragão, 2004). The strain B. sacchari LFM 101 was isolated from Brazilian sugarcane plantation soil (Brämer et al., 2001). Bacterial PHAs synthesis normally occurs more expressively when there is carbon source in excess and, simultaneously, at least one limiting nutrient, e.g. nitrogen, phosphorus or oxygen, essential for growth (Singh and Parmar, 2011). Once the polymer is synthesized as energy reserve, bacteria can later consume it when other available carbon sources have been exhausted. Thus, it is extremely important to understand the physiological behavior of bacteria.

The PHA-production cost is highly dependent on the price of the substrate (Lopes et al., 2014). As a consequence, PHAs are substantially more expensive than synthetic plastics. Sugarcane sucrose is a low cost alternative substrate. The integration of PHA production into sugarcane and ethanol mills can constitute a green cycle for bioplastic production (Nonato et al., 2001). Likewise, the use of residual glycerol from biodiesel production might foment low-cost PHA production (Squio and Aragão, 2004; Zhu et al., 2010).
There are studies in the literature on $B$. sacchari and PHA production from different substrates, but, for the mostpart, cells were grown at $30{ }^{\circ} \mathrm{C}$ (Silva et al., 2000; Mendonça et al., 2013; Lopes et al., 2014). Temperature is an important condition for bioprocesses. Changes in temperature may result in different microbial responses (Fonseca et al., 2013). Thus, this study aimed to evaluate the influence of Burkholderia sacchari LFM 101 on growth and PHA production, using glucose, sucrose or glycerol as carbon sources, at 30 or $35^{\circ} \mathrm{C}$.

\section{Materials and Methods}

\section{Microorganism and preservation}

Burkholderia sacchari LFM 101 were obtained lyophilized. Cells were reactivated by cultivation in 125 $\mathrm{mL}$-Erlenmeyer flasks shaken with $50 \mathrm{~mL}$ of nutrient broth ( $3 \mathrm{~g} \mathrm{~L}^{-1}$ of meat extract; $5 \mathrm{~g} \mathrm{~L}^{-1}$ of peptone) (24 $\left.\mathrm{h}, 30^{\circ} \mathrm{C}, 2.2 \times \mathrm{g}\right)$ and cryopreserved by the addition of $20 \%$ glycerol solution in the same proportion as the medium. The final solution (glycerol, $10 \% \mathrm{v} \mathrm{v}^{-1}$ ) containing the cells was distributed into $2 \mathrm{~mL}$ sterile microtubes, which were kept in a domestic freezer $\left(-18{ }^{\circ} \mathrm{C}, 40 \mathrm{~min}\right)$ before being stored at $-80{ }^{\circ} \mathrm{C}$ in an ultrafreezer.

Pre-cultures were prepared by transferring a loop from the frozen stock vial to a Petri plate containing nutrient broth agar $\left(48 \mathrm{~h}, 30^{\circ} \mathrm{C}\right)$. A loop from the plate was transferred to a $500 \mathrm{~mL}$-Erlenmeyer flask containing 250 $\mathrm{mL}$ of mineral medium (as described below) added from each carbon source. After 16-18 h of growth in an orbital shaker $(3.5 \times \mathrm{g})$ at 30 or $35{ }^{\circ} \mathrm{C}$ (depending on the temperature of the subsequent cultivation, which was the same), an aliquot (calculated $\left.\mathrm{OD}_{600}=0.1\right)$ was utilized as inoculum for the main cultivation in the same synthetic medium, as described below. 


\section{Culture medium}

Cultivations were performed in a defined mineral medium, containing (per liter of distilled $\mathrm{H}_{2} \mathrm{O}$ ): $\mathrm{KH}_{2} \mathrm{PO}_{4^{\prime}}$ $6.67 \mathrm{~g} ;\left(\mathrm{NH}_{4}\right)_{2} \mathrm{HPO}_{4}, 4 \mathrm{~g} ; \mathrm{MgSO}_{4} .7 \mathrm{H}_{2} \mathrm{O}, 0.8 \mathrm{~g} ; \mathrm{C}_{6} \mathrm{H}_{8} \mathrm{O}_{7}$. $\mathrm{H}_{2} \mathrm{O}, 0.8 \mathrm{~g}$; thiamine, $0.01 \mathrm{~g}$ and trace element solution, $0.5 \mathrm{~mL}$. The composition of the trace element solution was (per liter of $5 \mathrm{M} \mathrm{HCl}$ ): $\mathrm{FeSO}_{4} \cdot 7 \mathrm{H}_{2} \mathrm{O}, 10 \mathrm{~g}$; $\mathrm{CaCl}_{2}, 2 \mathrm{~g}$; $\mathrm{ZnSO}_{4} .7 \mathrm{H}_{2} \mathrm{O}, 2.2 \mathrm{~g} ; \mathrm{MnSO}_{4} \cdot 4 \mathrm{H}_{2} \mathrm{O}, 0.5 \mathrm{~g}$; $\mathrm{CuSO}_{4} .5 \mathrm{H}_{2} \mathrm{O}, 1 \mathrm{~g}$; $\left(\mathrm{NH}_{4}\right)_{6} \mathrm{Mo}_{2} 7 \mathrm{O}_{2} 4.4 \mathrm{H}_{2} \mathrm{O}, 0.1 \mathrm{~g} ; \mathrm{Na}_{2} \mathrm{~B}_{4} \mathrm{O}_{7} .10 \mathrm{H}_{2} \mathrm{O}, 0.02 \mathrm{~g}$ (Lee and Choi, 2001). All medium components, except the carbon source, and thiamine were sterilized by autoclaving at $121{ }^{\circ} \mathrm{C}$ for $15 \mathrm{~min}$. The solution containing the carbon source (glucose, sucrose or glycerol, $10 \mathrm{~g} \mathrm{~L}^{-1}$ ) was autoclaved separately and thiamine sterilized by filtration. All components were mixed after reaching room temperature.

\section{Cultivations}

Cultivations were performed in triplicate in 500 $\mathrm{mL}$ Erlenmeyer flasks with $250 \mathrm{~mL}$ working volume and started by adding a certain volume of the pre-culture, so that the initial cell concentration in the flask was $0.1 \mathrm{ab}-$ sorbance units at $600 \mathrm{~nm}\left(\mathrm{Abs}_{600}\right)$. Cultivation conditions were 30 or $35^{\circ} \mathrm{C}$, initial $\mathrm{pH}$ of 6.0 in an orbital shaker at $3.5 \times \mathrm{g}$.

Samples (maximum $4 \mathrm{~mL}$ every $1 \mathrm{~h}$ ) were collected regularly from the flasks in centrifuge tubes in an icewater bath; $2 \mathrm{~mL}$ were used for $\mathrm{OD}_{600 \mathrm{~nm}}$ measurement, after appropriate dilution (when necessary). The remaining $2 \mathrm{~mL}$ was centrifuged $\left(17,609.0 \times \mathrm{g}, 5 \mathrm{~min}, 5^{\circ} \mathrm{C}\right)$. The supernatant was frozen at $-80^{\circ} \mathrm{C}$ and later used for determining the concentration of extracellular metabolites. The pellet was utilized to determine the biomass concentration, by mass difference, in terms of grams of dry biomass weight per culture. The $\mathrm{pH}$ was obtained by potentiometric measurements (Hanna).

\section{Biomass determination}

The biomass pellet obtained after sample centrifugation was dried in an oven $\left(105^{\circ} \mathrm{C}\right)$ until constant weight. The dried cell mass $\left(\mathrm{g} \mathrm{L}^{-1}\right)$ was obtained by the quotient of the difference in weight by the volume of centrifuged medium. Biomass concentration (X) was also indirectly determined via optical density (OD) measurements taken with a spectrophotometer at $600 \mathrm{~nm}$. For this purpose, the absorbance values measured were converted into mass values using a linear relationship (OD units per gram dry cell mass) determined for each experiment.

\section{Determination of kinetic parameters}

The exponential growth phase (EGP) was identified as the linear region on an $\ln (\mathrm{X})$ vs. time plot for batch cultivation data. The maximum specific growth rate $\left(\mu_{\max }\right)$ was determined as the slope of this linear region. The biomass yield from substrate $\left(\mathrm{Y}_{\mathrm{X} / \mathrm{S}}\right)$ was determined as the slope of the line on an X vs. S plot, exclusively including points belonging to the EGP. The specific rate of substrate consumption $\left(\mu_{\mathrm{s}}\right)$ was calculated by the quotient of $\mu_{\max }$ by $\mathrm{Y}_{\mathrm{X} / \mathrm{S}}$. The maximum biomass concentration $\left(\mathrm{X}_{\max }\right)$ was indicated by the maximum dried cell mass concentration or $\mathrm{OD}_{600 \mathrm{~nm}}$ observed in each experiment. The remaining biomass $\mathrm{X}(\mathrm{R})$ was identifed by the difference between total biomass and accumulated polymer.

\section{Polymer extraction}

On reaching the stationary phase, experiments were stopped, centrifuged (202.9 $\times \mathrm{g}, 40 \mathrm{~min})$, and the biomass pellet was dried in an oven $\left(40{ }^{\circ} \mathrm{C}, 24 \mathrm{~h}\right)$. Extraction was performed by using a Soxhlet extractor with chloroform as solvent, during a $12 \mathrm{~h}$ flow. Then the solution was concentrated and the polymer precipitated with a $95 \%$ ethanol solution.

\section{Determination of extracellular metabolite concen- tration}

Glucose, glycerol, ethanol and organic acids were separated as described elsewhere (Fonseca et al., 2007), with some modification. They were determined by high performance liquid chromatography (HPLC) equipped with an Aminex HPX-87H ion-exclusion column $(300 \times$ $7.8 \mathrm{~mm}$ ). The column was eluted at $55^{\circ} \mathrm{C}$ using water acidified with trifluoroacetic acid (TFA) at $0.005 \mathrm{M}$ as mo-

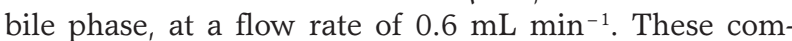
pounds were detected by a UV-absorbance detector at 254 $\mathrm{nm}$ connected in series with a differential refractometer detector (RID) coupled to a data acquisition module.

\section{PHA composition}

PHA composition was determined by gas chromatography of propyl esters, as described elsewhere (Mendonça et al., 2013). A volume of $1 \mathrm{~mL}$ of organic phase was analyzed after fractionation of the sample (split 1:25) in a gas chromatograph equipped with an HP-5 column (5\% phenyl methyl siloxane, $30 \mathrm{~m}$ in length, $0.25 \mathrm{~mm}$ in diameter, and 0:25 $\mu \mathrm{m}$ in film thickness). Analysis was conducted under the following conditions: carrier gas helium $\left(0.8 \mathrm{~mL} \mathrm{~min}^{-1}\right)$; injector temperature of $250{ }^{\circ} \mathrm{C}$; detector temperature of $300{ }^{\circ} \mathrm{C}$; detection system by flame ionization detector (FID), with the oven set at $100{ }^{\circ} \mathrm{C}$ for $1 \mathrm{~min}$, with a temperature increase up to $185^{\circ} \mathrm{C}$ at $8^{\circ} \mathrm{C}$ $\min ^{-1}$, thereafter maintained at $185^{\circ} \mathrm{C}$ for $15 \mathrm{~min}$. Benzoic acid was used as the internal standard.

\section{Statistical analysis}

The Statistica 8.0 software (Stat Soft, USA) was used to calculate the analysis of variance (ANOVA). The Tukey test was used to determine differences between the variables' temperature and substrate, with a $95 \%$ confidence interval.

\section{Results and Discussion}

Table 1 shows the kinetic parameters obtained from the experiments with glucose, sucrose and glycerol as unique carbon sources, at 30 and $35^{\circ} \mathrm{C}$ (glycerol only at $\left.30{ }^{\circ} \mathrm{C}\right)$. 
Table 1 - Kinetic parameters of the cultivations with Burkholderia sacchari LFM 101 from glucose, sucrose and glycerol at 30 and $35{ }^{\circ} \mathrm{C}$.

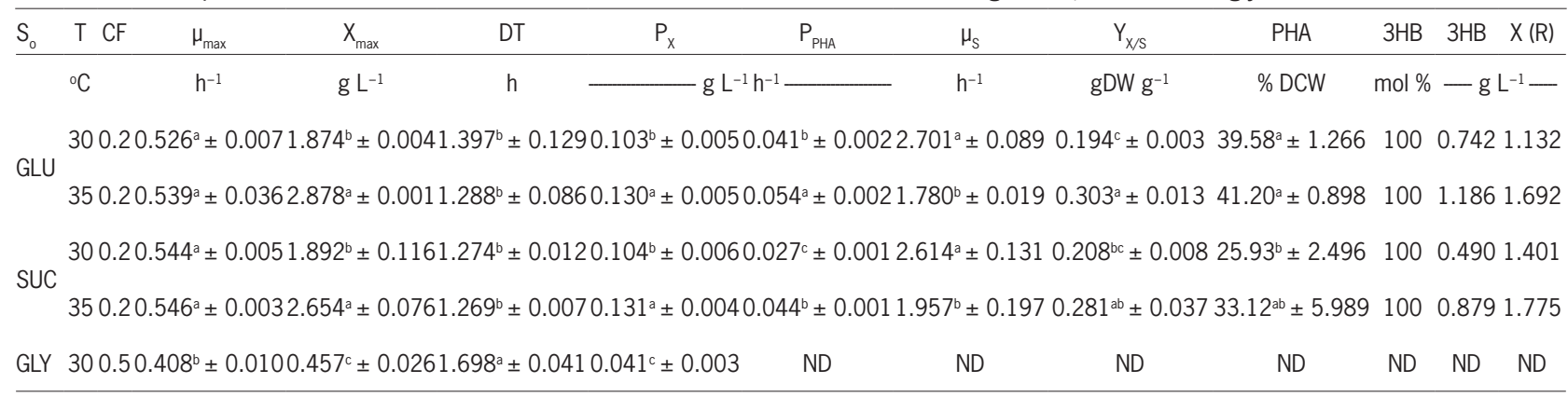

GLU: glucose; SUC: sucrose; GLY: glycerol; T: temperature; $S_{0}$ : initial substrate; DT: doubling time; $\mu_{\max }$ : maximum specific growth rate; $\mathrm{X}_{\max }$ : maximum biomass concentration; PHA: polyhydroxyalkanoate; DCW: dry cell weight; $\mu_{\mathrm{s}}$ : specific rate of substrate consumption; $Y_{\text {xs: }}$ specific rate of substrate consumption; $3 \mathrm{HB}$ : 3-hydroxybutyrate; CF: conversion factor of optical density $(600 \mathrm{~nm})$ into biomass; R: remaining; ND: not determined. Same letters in the same column were not significantly different $(p \geq 0.05)$.

When the maximum specific growth rate $\left(\mu_{\max }\right)$ values obtained with glucose and sucrose were compared, no difference $(p>0.05)$ between them was observed (an average of $\left.0.539 \mathrm{~h}^{-1}\right)$. A differences was seen in the case of glycerol only, whose $\mu_{\max }$ was $0.408 \mathrm{~h}^{-1}$. The $\mu_{\max }$ values were higher (except for glycerol) than that previously reported for Burkholderia sacchari IPT 101 with glucose as substrate $\left(\mu_{\max }=0.45 \mathrm{~h}^{-1}\right.$ ) (Gomez et al., 1996).

However, the highest PHA productivity $10.054 \mathrm{~g}$ $\mathrm{L}^{-1} \mathrm{~h}^{-1}$ ) was seen with glucose at $35{ }^{\circ} \mathrm{C}$. Experiments with both glucose and sucrose attained the stationary phase after approximately $19.5 \mathrm{~h}$, but with glycerol it was reached after only $6 \mathrm{~h}$.

The literature shows that Burkholderia sp. was able to grow between 25 and $37{ }^{\circ} \mathrm{C}$ with 28 to $30{ }^{\circ} \mathrm{C}$ as the optimal range (Lopes et al., 2014). In our study, $35^{\circ} \mathrm{C}$ was found to be the most favorable temperature for maximal $\mathrm{X}_{\max }$ and $\mathrm{P}_{\mathrm{x}}$ parameters for the Burkholderia sacchari strain.

The highest polymer yield was obtained with glucose at $35{ }^{\circ} \mathrm{C}(41 \%)$, a value greater than the results obtained by Mendonça et al. (2013) with the same strain after 24 hours of cultivation $132 \%$ PHA in its cell dry weight), using glucose (10 $\left.\mathrm{g} \mathrm{L}^{-1}\right)$ as the carbon source. It was also observed that, up to 24 hours of culture, the bacteria used the carbon and nitrogen sources for growth, and that after 24 hours, once the nitrogen had been exhausted, the excess of carbon present was used for PHA accumulation.

In this study, experiments were interrupted at the beginning of the stationary phase of growth because this coincided with the depletion of the carbon source, so there was no excess carbon for polymer accumulation (Figure 1).

It is observed that PHA productivity on sucrose at $35^{\circ} \mathrm{C}$ is equivalent to that obtained on glucose at 30 ${ }^{\circ} \mathrm{C}$ (Table 1). As reported by Squio and Aragão (2004), Burkholderia sacchari has great potential for industrial production, mainly because of its ability to consume sucrose. This potential was confirmed by Gomez (2006) in his study where Burkholderia sacchari IPT 101 /= LFM 101) was able to accumulate $75 \%$ of its dry weight in

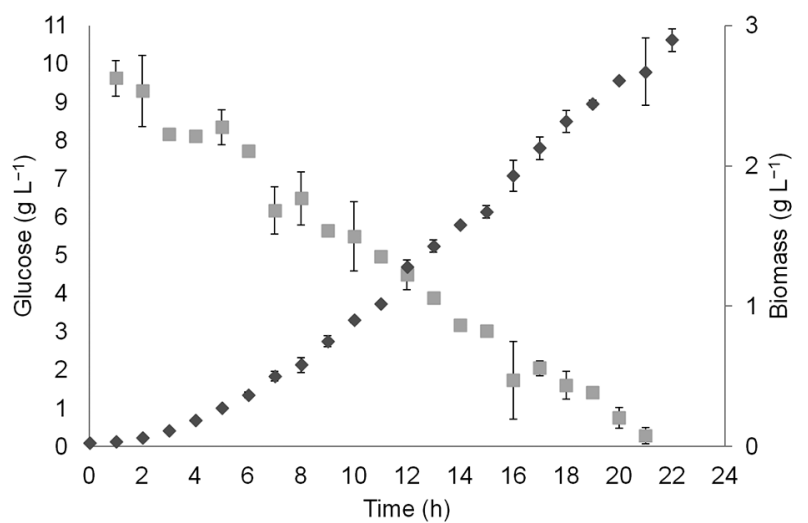

Figure 1 - Growth kinetics of Burkholderia sacchari LFM 101 with glucose as carbon source at $35^{\circ} \mathrm{C}$.

P3HB from glucose plus fructose and $69 \%$ from sucrose, with an efficiency higher than $80 \%$ of the maximum theoretical yield in 48 hour cultivations. Thus, it may be considered that, although a slightly smaller yield was observed on sucrose than on glucose, sucrose is still a very attractive carbon source for polymer production.

The type of polymer synthesized by the bacteria depends on the substrate used, as it determines which pathway will be utilized on it. In this study, for the substrates sucrose and glucose, $\mathrm{P} 3 \mathrm{HB}$ was the sole PHA monomer accumulated by Burkholderia sacchari LFM 101. There was no expressive production $\left(>0.1 \mathrm{~g} \mathrm{~L}^{-1}\right)$ in any of the evaluated metabolites.

The parameters related to substrate consumption were not calculated for the glycerol substrate. It was not considered feasible to continue with the analysis, since there was neither a significant glycerol consumption nor biomass formation. $\mathrm{X}_{\max }$ obtained was extremely low 10.46 $\mathrm{g} \mathrm{L}^{-1}$ ) (Table 1 ). In a previous study using synthetic medium with glycerol as the sole carbon source, cell growth was also found in yeast cultures, even when working with strains capable of consuming glycerol. However, growth was observed when yeast extract was added to the culture medium, which was related to trace compounds present 
in the yeast extract that would be essential for an effective assimilation of glycerol by yeasts (Rivaldi et al., 2012).

When glycerol is utilized as the sole carbon source, it is initially metabolized to dihydroxyacetone phosphate (Figure 2). For this, there are two possible pathways: one is dehydrogenation and the other phosphorylation. The first one is $\mathrm{NAD}^{+}$(oxidized nicotinamide adenine dinucleotide) and ATP (adenosine triphosphate) dependent, the second one is ATP and FAD (flavin adenine dinucleotide) dependent (Rivaldi et al., 2012). Then, dihydroxyacetone phosphate is directed at energy production and/ or PHA biosynthesis.

The glycerol assimilation is dependent on external electron receptors. The carbon source must ensure the overall redox balance within the cell. Therefore, the choice of the carbon source becomes a determinant factor if satisfactory product yields are to be obtained (Clomburg and Gonzalez, 2013).

Thus, in the experiment conducted with Burkholderia sacchari LFM 101 with glycerol as the sole carbon source, the poor growth could be attributed to no significant growth being observed due to the lack of energy $\left(\mathrm{NAD}^{+}\right.$; FAD; ATP) for breaking the glycerol molecule. The small biomass production is probably due to the consumption of the other nutrients present in the mineral medium, e.g. citric acid.

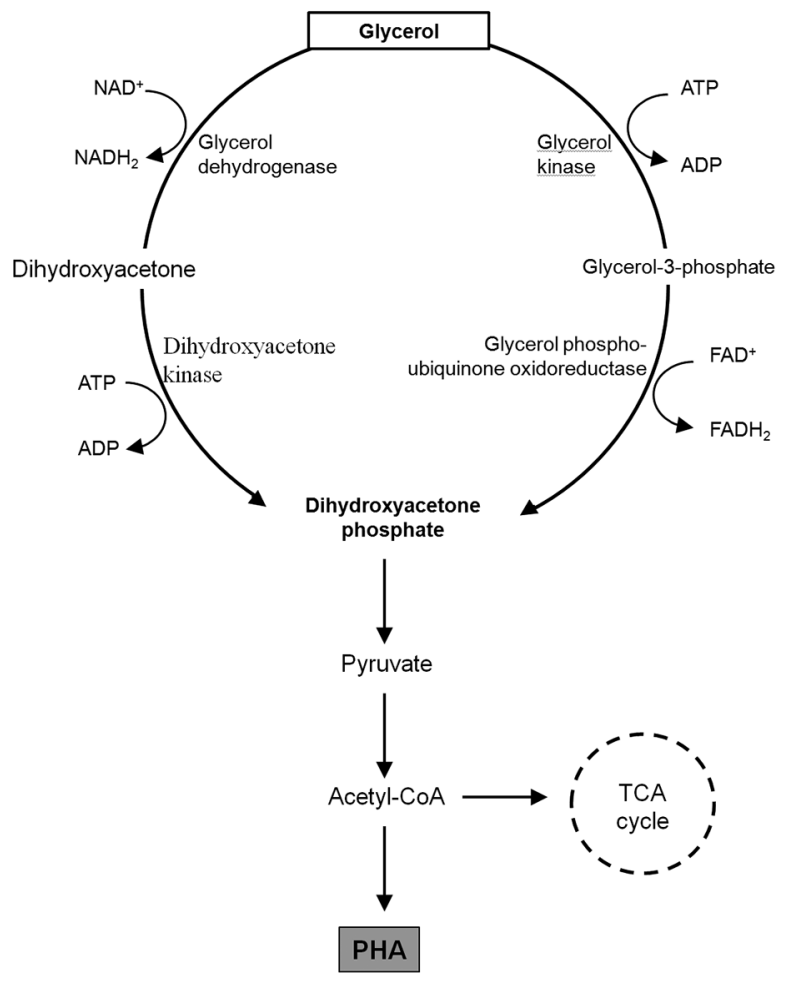

Figure 2 - Metabolic pathways for glycerol assimilation by microorganisms and polyhydroxyalkanoate (PHA) formation (adapted from Rivaldi et al., 2012).
A PHA yield of $10 \%$ for Burkholderia sacchari on glycerol (Rodríguez-Contreras et al., 2015) has been published elsewhere. However, glucose was utilized in the initial stages of cultivation, and glycerol as the sole carbon source only in the phase of PHA accumulation. Thus, it can be concluded that it is possible to produce polymers and cells from glycerol if cultivation is supplemented with another substrate that has the necessary energy for breaking glycerol molecules.

\section{Conclusion}

It was found that the Burkholderia sacchari LFM 101 presented the best results in cultures containing glucose at $35^{\circ} \mathrm{C}$. Although higher productivity was observed with glucose, sucrose revealed great potential for polymer accumulation by the bacterium under higher temperatures. The temperature did not influence the maximum specific growth rates $\left(\mu_{\max }\right)$, which remained around 0.54 $\mathrm{h}^{-1}$ for both the glucose and sucrose substrates. However, $B$. sacchari showed greater accumulation of polymer at 35 ${ }^{\circ} \mathrm{C}$, indicating that the temperature adjustment is important for optimizing the production of biopolymer from $B$. sacchari. The growth conditions analyzed were not favorable to glycerol consumption probably due to limitations in the energy supply from glycerol.

\section{References}

Brämer, C.O.; Silva, L.F.; Gomez, J.G.C.; Vandamme, P.; Steinbüchel, A. 2001. Burkholderia sacchari sp. nov., a polyhydroxyalkanoate- accumulating bacterium isolated from soil of a sugar cane plantation in Brazil. International Journal of Systematic and Evolutionary Microbiology 51: 1709-1713.

Clomburg, J.M.; Gonzalez, R. 2013. Anaerobic fermentation of glycerol: a platform for renewable fuels and chemicals. Trends in Biotechnology 31: 20-28.

Fonseca, G.G.; Carvalho, N.M.B.; Gombert, A.K. 2013. Growth of the yeast Kluyveromyces marxianus CBS 6556 on different sugar combinations as sole carbon and energy source. Applied Microbiology and Biotechnology 97: 5055-5067.

Fonseca, G.G.; Gombert, A.K.; Heinzle, E.; Wittmann, C. 2007. Physiology of the yeast Kluyveromyces marxianus during batch and chemostat cultures with glucose as the sole carbon source. FEMS Yeast Research 7: 422-435.

Gomez, J.G.C.; Rodrigues, M.F.A.; Alli, R.C.P.; Torres, B.B.; Bueno Netto, C.L.; Oliveira, M.S.; Silva, L.F. 1996. Evaluation of soil Gram-negative bacteria yielding polyhydroxyalkanoic acids from carbohydrates and propionic acid. Applied Microbiology and Biotechnology 45: 785-791.

Lee, S.Y.; Choi, J.L. 2001. Production of microbial polyester by fermentation of recombinant microorganisms. Advances in Biochemical Engineering and Biotechnology 71: 183-207.

Lopes, M.S.G.; Gomez, J.G.C.; Taciro, M.K.; Mendonça, T.T.; Silva, L.F. 2014. Polyhydroxyalkanoate biosynthesis and simultaneous remotion of organic inhibitors from sugarcane bagasse hydrolysate by Burkholderia sp. Journal of Industrial Microbiology and Biotechnology 41: 1353-1363. 
Mendonça, T.T.; Gomez, J.G.C.; Buffoni, E.; Sanchez Rodriguez, R.J.; Schripsema, J.; Lopes, M.S.G.; Silva, L.F. 2013. Exploring the potential of Burkholderia sacchari to produce polyhydroxyalkanoates. Journal of Applied Microbiology 116: 815-829.

Mousavioun, P.; Halley, P.J.; Doherty, W.O.S. 2013. Thermophysical properties and rheology of $\mathrm{PHB} /$ lignin blends. Industrial Crops and Products 50: 270-275.

Nonato, R.V.; Mantelatto, P.E.; Rossell, C.E.V. 2001. Integrated production of biodegradable plastic, sugar and ethanol. Applied Microbiology 57: 1-5.

Rivaldi, J.D.; Sarrouh, B.F.; Branco, R.F.; Mancilha, I.M.; Silva, S.S. 2012. Biotechnological utilization of biodiesel-derived glycerol for the production of ribonucleotides and microbial biomass. Applied Biochemistry and Biotechnology 167: 20542067.

Rodríguez-Contreras, A.; Koller, M.; Dias, M.M.S.; CalafellMonforte, M.; Braunegg, G.; Marqués-Calvo, M.S. 2015. Influence of glycerol on poly(3-hydroxybutyrate) production by Cupriavidus necator and Burkholderia sacchari. Biochemical Engineering Journal 94: 50-57.
Silva, L.F.; Gomez, J.G.C.; Oliveira, M.S.; Torres, B.B. 2000. Propionic acid metabolism and poly-3-hydroxybutyrate-co-3hydroxyvalerate (P3HB-co-3HV) production by Burkholderia sp. Journal of Biotechnology 76: 165-174.

Singh, P.; Parmar, N. 2011. Isolation and characterization of two novel polyhydroxybutyrate (PHB)-producing bacteria. African Journal of Biotechnology 10: 4907-4919.

Squio, C.R.; Aragão, G.M.F. 2004. Cultivation strategies for production of the biodegradable plastics poly/3hydroxybutyrate) and poly(3-hydroxybutyrate-co-3hydroxyvalerate) by bacteria. Química Nova 27: 615-622 (in Portuguese, with abstract in English).

Zhu, C.; Nomura, C.T.; Perrotta, J.A.; Stipanovic, A.J.; Nakas, J.P. 2010. Production and characterization of poly-3hydroxybutyrate from biodiesel-glycerol by Burkholderia cepacia ATCC 17759. Biotechnology Progress 26: 424-430. 